\title{
ONE-POT SYNTHESIS OF 1,4-DIHYDROPYRIDINE DERIVATIVES AND THEIR X-RAY CRYSTAL STRUCTURES: ROLE OF FLUORINE IN WEAK INTERACTIONS
}

\begin{abstract}
R. Shashi ${ }^{1}$, N. L. Prasad ${ }^{1}$, and N.S. Begum ${ }^{1}$ *
1,4-dihydropyridines, namely diethyl 4-(4-fluorophenyl)-2,6-dimethyl-1,4-dihydropyridine-3,5-dicarboxylate (1a), diethyl 2,6-dimethyl-4-(3,4,5-trimethoxyphenyl)-1,4-dihydropyridine-3,5-dicarboxylate(1b), and diethyl 4-(3,4-dimethoxyphenyl)-2,6-dihydroxy-2,6-bis(trifluoromethyl)piperidine-3,5-dicarboxylate $\quad$ (2), are synthesized by one-pot multicomponent condensation of aromatic aldehyde with ethyl acetoacetate and liquid ammonia in the presence of an ethanol-water mixture and are characterized by single crystal X-ray diffraction. The effect of a fluorine atom on the dihydropyridine nucleus give insight into the self-assembly of compounds with various types of non-covalent interactions that greatly affect the crystal packing.
\end{abstract}

DOI: $10.1134 / \mathrm{S} 0022476620060141$

Keywords: 1,4-dihydropyridines, crystal structure, intermolecular interactions.

\section{INTRODUCTION}

Dihydropyridines (DHPs), in particular 4-aryl-substituted 1,4-dihydropyridines, have been recognized as an important class of organic compounds for their calcium channel modulator activity and they are used in the treatment of cardiovascular diseases [1,2]. They are pharmacologically active compounds [3]. In a series of biological assays, these compounds were found to have a remarkable significance because of their wide range of pharmacological and biological activities: in treating cardiovascular diseases, hypertension [3], anti-inflammatory [4], antiviral [5], cytotoxicity [6], anticonvulsants [7], anti-tuberculosis [8], antithrombotic [9], Alzheimer's disease [10], calcium agonists and antagonists [11], and more recently as enhancers of vanilloid receptor 1 (TRPV1) [12]; they are screened as the human multidrug resistance protein [13]. The diverse bioactivity of the 1,4-dihydropyridine nucleus has led to interest in the synthesis of these compounds to elucidate the molecular basis of their action and to improve their pharmacological profile.

Carbon-fluorine (C-F) bond serves as a molecular tag for many applications in medicinal chemistry and oncology. Fluorination, is a chemical process to add a fluorine atom into a single molecule or a complex matrix materials (e.g. compounds), which is largely used in the pharmaceutical field to confer some interesting bioactivities. Further, it is more recently used for labelling some biological molecules of interest (i.e. peptides, nucleic acids) or nanomaterials (i.e. nanoparticles) which are of high importance for cancer chemo- and biotherapy (e.g. immunotherapy) as well as tumour/cancer imaging.

${ }^{1}$ Department of Studies in Chemistry, Bangalore University, Bangalore, Karnataka, India; *noorsb05@gmail.com. Original article submitted August 16, 2019; revised November 16, 2019; accepted November 20, 2019. 
Intermolecular interactions play a primary role in the supramolecular assembly in molecular crystals. The most prominent supramolecular interactions are those formed by hydrogen bonds involving halogen atoms. A halogen atom, such as fluorine, in molecular crystals mediate interactions with heteroatoms, e.g. nitrogen, oxygen, and sulphur, and they exhibit a crucial role in crystal packing and serve to direct individual components to self-assemble in an organised manner [14]. The formation of new organic compounds are often associated with the $\mathrm{F}$ atom substitution for $\mathrm{H}$, which led to the formation of new supramolecular synthons and motifs [15]. For instance, in compound $\mathbf{1 b}$ there is a radical change in crystal packing when the methyl group $\mathrm{H}$ atom of $\mathrm{C} 1$ and $\mathrm{C} 7$ atoms of compound 1a is replaced by $\mathrm{F}$ atoms. Hence, a change in the supramolecular architecture of a crystal in turn affects the physical and chemical properties of compounds caused by their electronegativity, low polarizability, and bond strength, even the electron density distribution. Several papers have also demonstrated the advantages of fluoroorganic compounds over non-fluorinated analogs in definite applications [16, 17].

DHPs were first synthesized by Hantzsch in 1882 via the three-component synthesis [18] using an aldehyde, ethyl acetoacetate, and ammonium acetate in ethanol or acetic acid at $80^{\circ} \mathrm{C}$. This reaction was further fine-tuned by the development of several synthetic strategies and methodologies, including microwave irradiation [19], ultrasound [20], ionic liquids [21], phase transfer catalysts [22], Brønsted bases [23], solvent free synthesis [24], Lewis acids [25], Brønsted acids [26], and Lewis base [27], catalyzed solvent free synthesis of DHPs.

\section{EXPERIMENTAL}

Materials and methods. Melting points were determined in open capillaries using a Guna melting point apparatus and are uncorrected. The IR spectra were recorded on a Nicolet Impact 400D FTIR spectrophotometer using KBr pellets. $\mathrm{H}^{1}$ and $\mathrm{C}^{13}$ NMR spectra were measured on a Bruker $400 \mathrm{MHz}$ NMR spectrometer in $\mathrm{CDCl}_{3}$ with TMS as the internal standard. The reactions and product purity were monitored by TLC silica gel plates. Mass spectra were recorded on a Finnigan MAT (Model MAT8200) spectrometer.

Experimental procedure for the synthesis of diethyl 4-(4-fluorophenyl)-2,6-dimethyl-1,4-dihydropyridine-3,5dicarboxylate (1a), diethyl 2,6-dimethyl-4-(3,4,5-trimethoxyphenyl)-1,4-dihydropyridine-3,5-dicarboxylate (1b), and diethyl 4-(3,4-dimethoxyphenyl)-2,6-dihydroxy-2,6-bis(trifluoromethyl)piperidine-3,5-dicarboxylate (2). A mixture of an aromatic aldehyde (1 $\mathrm{mmol})$, ethyl acetoacetate $(\mathbf{1 a}, \mathbf{b})$, trifluroethylacetoacetate $(\mathbf{2})(2 \mathrm{mmol})$, and aqueous ammonia (1.5 mmol) was refluxed in an ethanol-water mixture for 4-6 h, as shown in Scheme 1. The compounds are listed in Table 1. The reaction progress was monitored by TLC. After confirming that the reaction was complete, the reaction mixture was cooled to room temperature and allowed to stand for two days to ensure the formation of a solid. The resulting solid product was washed with methanol and recrystallized from an ethanol solution to yield single crystals suitable for X-ray diffraction studies.

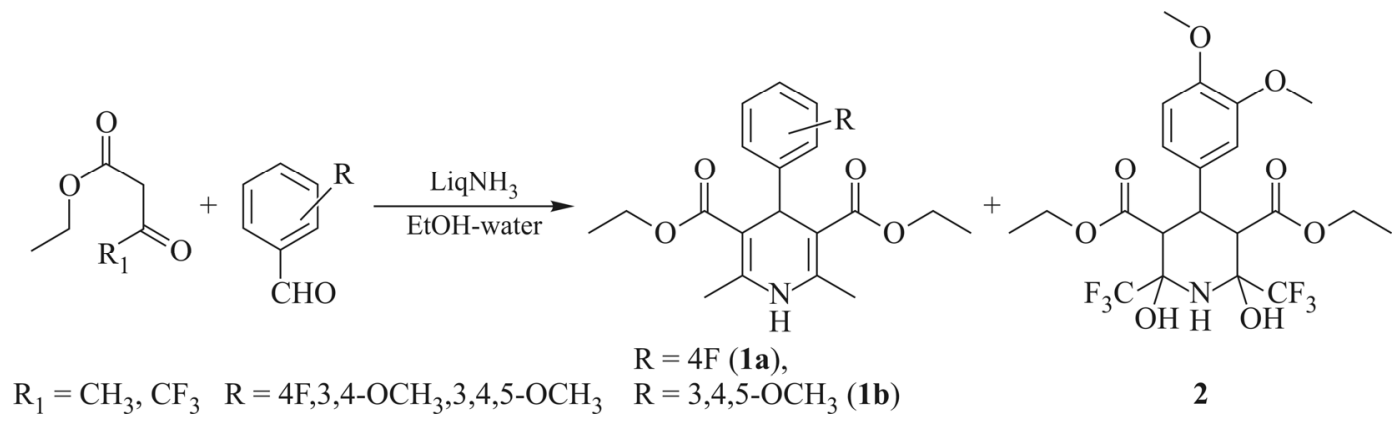

Scheme 1. Syntheses of 1,4-dihydropyridines.

Physical measurements. Diethyl 4-(4-fluorophenyl)-2,6-dimethyl-1,4-dihydropyridine-3,5-dicarboxylate (1a). MS (m/z): $346 \mathrm{M}-1,311,265$. Elemental analysis: C 65.58 (64.77), H 6.38(7.09), N 4.56 (3.68). $\mathrm{H}^{1} \mathrm{NMR}$ : 1.23(6H, s), 2.31(6H, s), 4.02-4.03 (4H, q), 4.94 (1H, s), 7.11 (2H, t), 7.42 (2H, ddd). $\mathrm{C}^{13}$ NMR, $\delta(p p m): 115.43667,115.43667,129.79$, 
TABLE 1. Synthesized and Crystallized Compounds

\begin{tabular}{|c|c|c|c|c|}
\hline Compound & R/Substituents Chemical Formula & Yield, $\%$ & Time, $\mathrm{h}$ & Melting point, ${ }^{\circ} \mathrm{C}$ \\
\hline 1a & & 82 & 6 & $132-135$ \\
\hline $\mathbf{1 b}$ & & 83 & 5 & $148-150$ \\
\hline 2 & & 78 & 5 & $167-169$ \\
\hline
\end{tabular}

$129.79,40,104.1,104.1,14.13877,14.13877,146.8125,146.8125,60.73721,60.73721,166.92571,166.92571,145.1384$, 163.35171, 19.13, 19.13. IR ( $\left.\mathrm{cm}^{-1}\right): 1600-1700$ (ester), 1400-1500 (ester).

Diethyl 2,6-dimethyl-4-(3,4,5-trimethoxyphenyl)-1,4-dihydropyridine-3,5-dicarboxylate (1b). MS $(\mathrm{m} / \mathrm{z})$ : $419.38 \mathrm{M}$, 390.29, 252.27. Elemental analysis: C 62.99, H 6.97, N 3.34, O 26.70. $\mathrm{H}^{1} \mathrm{NMR}, \delta(\mathrm{ppm}): 1.23$ (6H, t), 2.34 (6H, s), 3.79 (3H, s), $3.93(6 \mathrm{H}, \mathrm{s}), 4.08-4.16(4 \mathrm{H}, \mathrm{q}), 4.94(1 \mathrm{H}, \mathrm{s}), 6.51(2 \mathrm{H}, \mathrm{d}) . \mathrm{C}^{13} \mathrm{NMR}, \delta(\mathrm{ppm}): 167.836,60.970,59.988,56.233,105.400$, 152.909, 14.594, 143.543, 104.384, 143.881, 39.925, 19.854. IR ( $\left.\mathrm{cm}^{-1}\right)$ : 1700-1750 (ketone), 1500-1400 (ester).

Diethyl 4-(3,4-dimethoxyphenyl)-2,6-dihydroxy-2,6-bis(trifluoromethyl)piperidine-3,5-dicarboxylate (2). MS ( $\mathrm{m} / \mathrm{z})$ : $534 \mathrm{M}+1$, 371. Elemental analysis: C 62.99, H 6.97, N 3.34, O 26.70. $\mathrm{H}^{1} \mathrm{NMR}: 1.46(6 \mathrm{H}, \mathrm{t}), 3.21(2 \mathrm{H}, \mathrm{d}), 3.85(3 \mathrm{H}, \mathrm{s})$, $3.90(3 \mathrm{H}, \mathrm{s}), 4.00-4.05(4 \mathrm{H}, \mathrm{q}), 5.12(1 \mathrm{H}, \mathrm{s}), 7.31-7.34(2 \mathrm{H}, \mathrm{m}) . \mathrm{C}^{13} \mathrm{NMR}: 148.74,122.79,124.55,112.40,110.38,76.71$, $62.18,56.04,48.41,40.90,13.4$. IR $\left(\mathrm{cm}^{-1}\right)$ : 3400-3500 (hydroxyl), 1600-1700 (ketone), 1500-1400 (ester).

X-ray diffraction analysis. Suitable crystals of compounds $\mathbf{1 a}, \mathbf{1 b}$, and $\mathbf{2}$ of the appropriate quality for single crystal X-ray diffraction were obtained by slow evaporation using ethanol as a solvent at room temperature. In each case, a good quality single crystal was mounted along its largest dimension and used for data collection. The intensity data were collected on a Bruker Smart CCD Area Detector System using $\operatorname{Mo} K_{\alpha}(0.7103 \AA)$ radiation in the $\omega-\varphi$ scan mode. The data were reduced using SAINT-Plus [28]. In each case, the structures were solved by direct methods and refined on $F^{2}$ using the SHELX-97 [29] software package. All the non-hydrogen atoms were refined anisotropically. Since the hydrogen atoms were not readily revealed from difference Fourier maps, they were included in the ideal positions with fixed isotropic $U$ values, and let riding on their respective non-hydrogen atoms. The mean plane calculations were made using the PARST program [30]. Diagrams were generated using ORTEP-3 [31], and DIAMOND [32].

Compound 1a. Intensity data were collected at $293 \mathrm{~K}$ in the $\omega-\varphi$ scan mode. A total of 19545 reflections were collected, resulting in $3035(R(\mathrm{int})=0.0418)$ independent reflections, out of which the number of reflections satisfying the $I>2 \sigma(I)$ criterion was 3035 . The $R$ factor for the observed data finally converged to $R=0.0383$. 
Compound 1b. Intensity data were collected at $293 \mathrm{~K}$ in the $\omega-\varphi$ scan mode. A total of 13229 reflections were collected, resulting in $3813(R(\mathrm{int})=0.0353)$ independent reflections, out of which the number of reflections satisfying $I>2 \sigma(I)$ criteria was 4105 . The $R$ factor for the observed data finally converged to $R=0.0468$.

Compound 2. Intensity data were collected at $293 \mathrm{~K}$ in the $\omega-\varphi$ scan mode. A total of 14090 reflections were collected, resulting in $4105(R(\mathrm{int})=0.0306)$ independent reflections, out of which the number of reflections satisfying $I>2 \sigma(I)$ criteria was 4105 . The $R$ factor for the observed data finally converged to $R=0.0478$.

\section{RESULTS AND DISCUSSION}

Chemistry of the carbon-fluorine bond. The $\mathrm{C}-\mathrm{F}$ bond is the most polar bond in organic chemistry, thus, the bond has a relatively large dipole moment with a significant negative charge density on the fluorine atom, and correspondingly, a positive charge density on the carbon atom [33]. Since the C-F bond has a much greater dipole moment than the carbonhydrogen $(\mathrm{C}-\mathrm{H})$ bond, a stronger binding with dipolar water might be expected [34]. The electrostatic nature of the $\mathrm{C}-\mathrm{F}$ bond renders it the strongest one in organic chemistry [33]. Further, C-F displays isoelectronic effects to the oxygen $(-\mathrm{O})$ atom and the hydroxyl $(-\mathrm{OH})$ group, and the high fluorine electronegativity $(-\mathrm{F})$ frequently alerts the chemical reactivity. However, the $(-\mathrm{F})$ atom itself is almost non-polarizable, and thus, despite the charge localization on $(-\mathrm{F})$, it is a poor hydrogen-bonding acceptor [30]. Overall, fluorination displays the following properties [35]: (i) enhancement of thermal stability (C-F: $107 \mathrm{kcal} / \mathrm{mol}$ ); (ii) increase in lipophilicity and hydrophobicity; (iii) improvement of the molecular bioavailability; and (iv) capability of mimicking enzyme-substrate interactions.

Chemistry of 1,4-dihydropyridine. The basic skeleton of 1,4-DHP is a doubly unsaturated six- membered cyclic system with one heteroatom and two double bonds. Owing to these double bonds and the lone pair on the $\mathrm{N}$ atom, this skeleton is prone to react with electrophilic reagents. While the lone pair on the $\mathrm{N}$ atom confers basicity to the compounds containing this skeleton; $\pi$ electrons in the double bonds facilitate the reactions with electron deficient species such as carbocations. Two equivalent and isoenergetic resonance forms can be written for 1,4-DHP. Clearly, positions 3 and 5 hold formal negative charges in these rigid forms, and are more likely to react with electrophiles when reacting with alkyl or aryl halides. 1,4-DHP typically yields mono- or disubstituted alkyl or aryl derivatives. The potency and activity of 1,4-DHP is related to its structure. It is possible that the basicity of the $\mathrm{N}$ atom in 1,4-DHP is critical to the function of 1,4-DHP-based drugs in their ability to bind to calcium and act as calcium channel blockers. The $\mathrm{N}$ atom in 1,4-DHP is an aliphatic tertiary nitrogen atom that is more basic than the pyridyl $\mathrm{N}$ atom.

Compounds 1a, 1b, and $\mathbf{2}$ were synthesized by the following procedure (Scheme 1). Ethyl acetoacetate reacts with 4-flurobenzaldehyde (1a) and 3,4,5-trimethoxy benzaldehyde (1) in the presence of liquid ammonia, resulting in the formation of compounds $\mathbf{1 a}$ and $\mathbf{1 b}$, whereas in compound 2, 2,2,2-trifluroethylacetoacetate reacts with 3,4-dimethoxybenzaldehyde to result in the formation of compound 2. Therefore, in compound 2, the C1 and C7 methyl groups are replaced by the trifluromethyl group, resulting in various weak interactions. The reaction mixtures were refluxed for about 5-6 $\mathrm{h}$ followed by recrystallization from ethanol, resulting in the formation of compounds $\mathbf{1 a}, \mathbf{1 b}$, and $\mathbf{2}$. The structures were confirmed by MS, ${ }^{1} \mathrm{H}$ and ${ }^{13} \mathrm{C}$ NMR, and IR techniques.

The crystal structures of compounds $\mathbf{1 a}$ and $\mathbf{1 b}$ are stabilized by intermolecular $\mathrm{C}-\mathrm{H} \cdots \mathrm{O}$ and $\mathrm{N}-\mathrm{H} \cdots \mathrm{O}$ interactions (Figs. 2 and 3), and compound 2 is stabilised by intermolecular $\mathrm{C}-\mathrm{H} \cdots \mathrm{O}, \mathrm{C}-\mathrm{H} \cdots \mathrm{F}, \mathrm{O}-\mathrm{H} \cdots \mathrm{O}$, and $\mathrm{N}-\mathrm{H} \cdots \mathrm{F}$ interactions.

Crystallographic studies. The summary of crystallographic data and other structure refinement parameters of compounds 1a, $\mathbf{1 b}$, and $\mathbf{2}$ are given in Table 5. Tables 2, 3, and 4 give the interatomic interaction parameters. The ORTEP view of 1a, 1b, and $\mathbf{2}$ molecules with atomic labeling (thermal ellipsoids drawn at a 50\% probability) is shown in Fig. 1. The molecular packing of compounds $\mathbf{1 a}, \mathbf{1 b}$, and $\mathbf{2}$ is illustrated in Figs. 2, 3, and 4.

Compound 1a crystallizes in the monoclinic crystal system, the $P 2_{1} / c$ space group with one molecule in the asymmetric unit. Similarly, compound $\mathbf{1 b}$ crystallizes in the orthorhombic system, the $P 2_{1} 2_{1} 2_{1}$ space group, and compound $\mathbf{2}$ crystallizes in the triclinic crystal system, the $P-1$ space group with one molecule in the asymmetric unit. 
TABLE 2. Non-Bonding Interactions and Possible Hydrogen Bonds $(\AA)$ for Compound 1a (D - Donor, A - Acceptor, $\mathrm{H}$ - Hydrogen)

\begin{tabular}{c|c|c|c|c}
\hline $\mathrm{D}-\mathrm{H} \cdots \mathrm{A}$ & $\mathrm{D}-\mathrm{H}$ & $\mathrm{H} \cdots \mathrm{A}$ & $\mathrm{D} \cdots \mathrm{A}$ & $\mathrm{D}-\mathrm{H} \cdots \mathrm{A}$ \\
\hline $\mathrm{N} 1-\mathrm{H} 1 \cdots \mathrm{O} 3^{\mathrm{i}}$ & 0.860 & 2.078 & 2.928 & 169.65 \\
$\mathrm{C} 18-\mathrm{H} 18 \cdots \mathrm{O} 1^{\mathrm{ii}}$ & 0.930 & 2.405 & 3.299 & 161.31
\end{tabular}

Symmetry codes: ${ }^{\mathrm{i}} x, y+1, z ;{ }^{\mathrm{ii}}-x+2,+y-1 / 2,-z+1 / 2$.

TABLE 3. Non-Bonding Interactions and Possible Hydrogen Bonds $(\AA)$ for Compound $\mathbf{1 b}(\mathrm{D}-$ Donor, $\mathrm{A}-\mathrm{Acceptor}$, $\mathrm{H}$ - Hydrogen)

\begin{tabular}{c|c|c|c|c}
\hline $\mathrm{D}-\mathrm{H} \cdots \mathrm{A}$ & $\mathrm{D}-\mathrm{H}$ & $\mathrm{H} \cdots \mathrm{A}$ & $\mathrm{D} \cdots \mathrm{A}$ & $\mathrm{D}-\mathrm{H} \cdots \mathrm{A}$ \\
\hline $\mathrm{N} 1-\mathrm{H} 1 \cdots \mathrm{O} 6^{\mathrm{i}}$ & 0.860 & 2.423 & 3.179 & 147.00 \\
$\mathrm{~N} 1-\mathrm{H} 1 \cdots \mathrm{O} 7^{\mathrm{i}}$ & 0.860 & 2.399 & 3.143 & 145.06 \\
$\mathrm{C} 7-\mathrm{H} 7 \mathrm{~A} \cdots 4^{\mathrm{ii}}$ & 0.960 & 2.651 & 3.595 & 167.83 \\
$\mathrm{C} 12-\mathrm{H} 12 \mathrm{~B} \cdots \mathrm{O} 2^{\mathrm{iii}}$ & 0.970 & 2.657 & 3.612 & 168.20
\end{tabular}

Symmetry codes: ${ }^{\text {i }}-x,+y-1 / 2,-z+1 / 2 ;{ }^{\text {ii }} x-1,+y,+z ;{ }^{\text {iii }} x+1,+y,+z$.

TABLE 4. Non-bonding Interactions and Possible Hydrogen Bonds $(\AA)$ for Compound 2 (D - Donor, A - Acceptor, $\mathrm{H}$ - Hydrogen)

\begin{tabular}{c|c|c|c|c}
\hline $\mathrm{D}-\mathrm{H} \cdots \mathrm{A}$ & $\mathrm{D}-\mathrm{H}$ & $\mathrm{H} \cdots \mathrm{A}$ & $\mathrm{D} \cdots \mathrm{A}$ & $\mathrm{D}-\mathrm{H} \cdots \mathrm{A}$ \\
\hline $\mathrm{N} 1-\mathrm{H} 1 \cdots \mathrm{F} 2^{\mathrm{i}}$ & 0.880 & 2.246 & 3.119 & 171.55 \\
$\mathrm{O} 7-\mathrm{H} 19 \cdots \mathrm{C} 19^{\mathrm{ii}}$ & 0.950 & 2.378 & 3.313 & 167.96 \\
$\mathrm{O} 7-\mathrm{H} 7 \cdots \mathrm{O} 3^{(\mathrm{v})}$ & 0.820 & 2.299 & 2.891 & 129.30 \\
$\mathrm{O} 8-\mathrm{H} 8 \cdots \mathrm{O} 1^{(\mathrm{vi})}$ & 0.819 & 2.224 & 2.832 & 131.17 \\
$\mathrm{C} 12-\mathrm{H} 12 \mathrm{~B} \cdots \mathrm{O} 6^{\mathrm{iii}}$ & 0.980 & 2.487 & 3.437 & 160.84 \\
$\mathrm{C} 16-\mathrm{H} 16 \cdots 5^{(\mathrm{iv})}$ & 0.950 & 2.423 & 3.270 & 148.38
\end{tabular}

Symmetry codes: ${ }^{\mathrm{i}}-x+1,-y,-z ;{ }^{\mathrm{ii}}-x,-y+1,-z+1 ;{ }^{\mathrm{iii}}-x+1,-y+1,-z ;{ }^{\mathrm{iv}}-x+1,-y,-z ;{ }^{\mathrm{v}} x, y+1, z+1 ;{ }^{\mathrm{vi}} x, y-1, z-1$.

In compound 1a, the 4-flurophenyl ring makes a dihedral angle of $87.23(6)^{\circ}$ with the pyridine ring. Compound $\mathbf{1 b}$ makes a dihedral angle of $88.61(5)^{\circ}$ with 3,4,5-trimethoxyphenyl and pyridine rings, and in compound 2 , the 1,4-dihydropyridine ring is inclined with the 3,4-dimethoxy phenyl ring with a dihedral angle of $70.49(1)^{\circ}$. In all the three cases, plane 1 is the pyridine ring $(\mathrm{N} 1, \mathrm{C} 2, \mathrm{C} 3, \mathrm{C} 4, \mathrm{C} 5$, and $\mathrm{C} 6)$ and plane 2 is the phenyl ring $(\mathrm{C} 14, \mathrm{C} 15, \mathrm{C} 16, \mathrm{C} 17, \mathrm{C} 18$, and C19).

In compound 1a, one of the ethylcarboxylate substituents on the dihydropyridine ring adopts the cis orientation and the other adopt the trans orientation between the carbonyl oxygen atom and the adjacent methyl groups with respect to $\mathrm{C} 2=\mathrm{C} 3$ and $\mathrm{C} 5=\mathrm{C} 6$ double bonds, respectively. In contrast, compounds $\mathbf{1 b}$ and $\mathbf{2}$ show both cis orientations between the carbonyl oxygen atoms and the adjacent methyl and trifluoromethyl groups with respect to the $\mathrm{C} 2=\mathrm{C} 3$ and $\mathrm{C} 5=\mathrm{C} 6$ bonds, respectively.

In compound 1a, the central pyridine ring adopts the boat conformation, with $\mathrm{C} 4$ and $\mathrm{N} 1$ atoms deviating by $0.396(9) \AA$ and $-0.160(0) \AA$, respectively, from the mean plane of the other four $\mathrm{C} 2 / \mathrm{C} 3 / \mathrm{C} 5 / \mathrm{C} 6$ atoms in the pyridine ring. In compound $\mathbf{1 b}$, the central pyridine ring adopts a slight boat conformation, with $\mathrm{C} 4$ and $\mathrm{N} 1$ atoms deviating by $-0.2668 \AA$ and 
TABLE 5. Crystallographic Data and Other Structure Refinement Parameters of Compounds 1a, $\mathbf{1 b}$ and $\mathbf{2}$

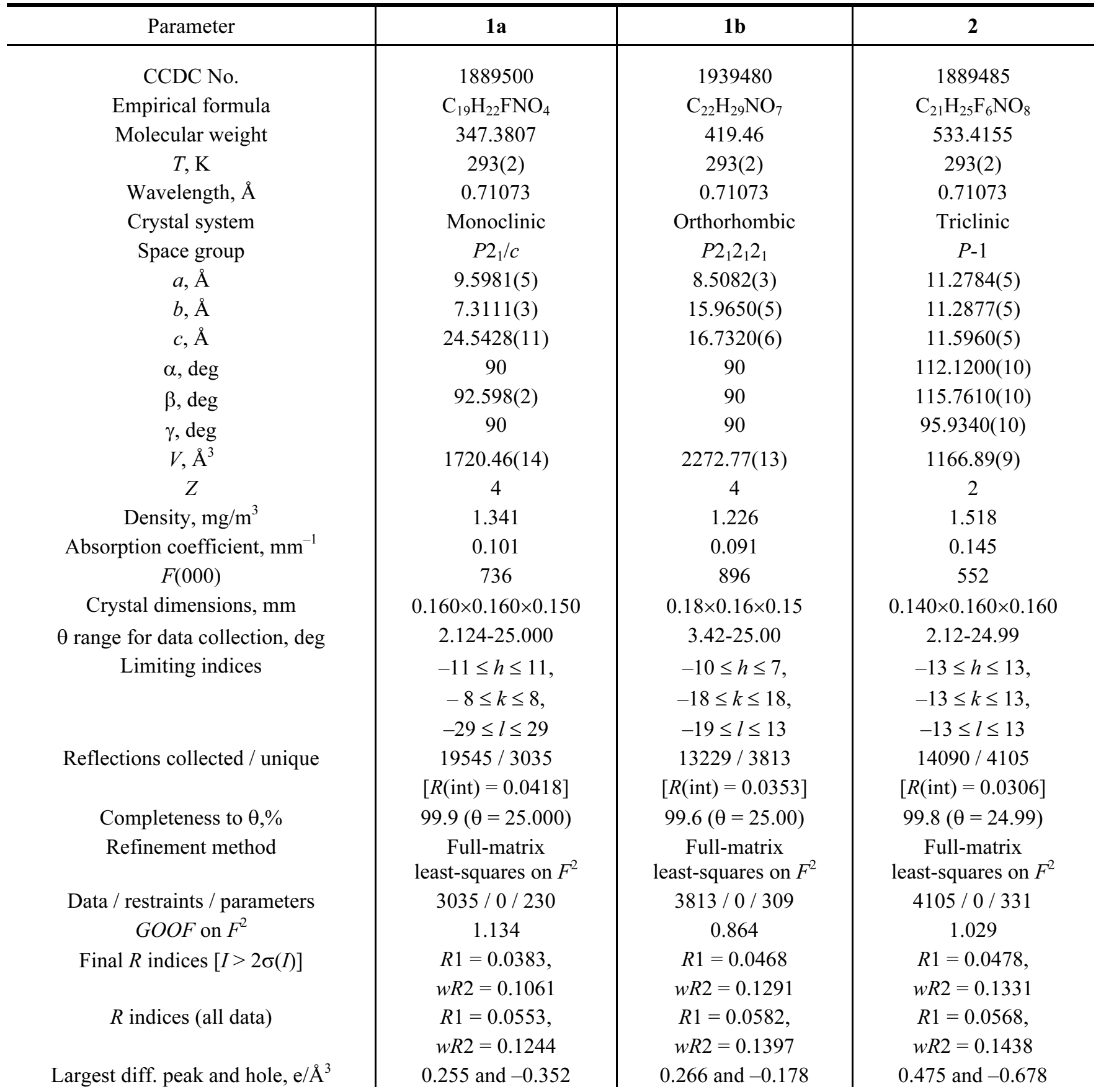

$-0.1311 \AA$ from the other atoms in the pyridine ring, and in compound 2 , the central pyridine ring adopts the half-chair conformation with $\mathrm{C} 4$ and N1 atoms, deviating by $-0.728(5) \AA$ and $0.548(9) \AA$, respectively, from the mean plane of the other four $\mathrm{C} 2 / \mathrm{C} 3 / \mathrm{C} 5 / \mathrm{C} 6$ atoms in the ring.

Refinement of the disorder. In compound 2, all $\mathrm{H}$ atoms were included in the calculated positions, with $\mathrm{C}-\mathrm{H}$ bond distances of $0.93 \AA$ and were refined in a riding model approximation with $U_{\text {iso }}(\mathrm{H})=1.1 U_{\text {eq }}(\mathrm{C}, N)$. The carbonyl O4 oxygen atom and the two $\mathrm{C} 10$ and $\mathrm{C} 13$ methyl groups are disordered over two sites with an occupancy factor of 0.60 and 0.40 for the major and minor components respectively. 

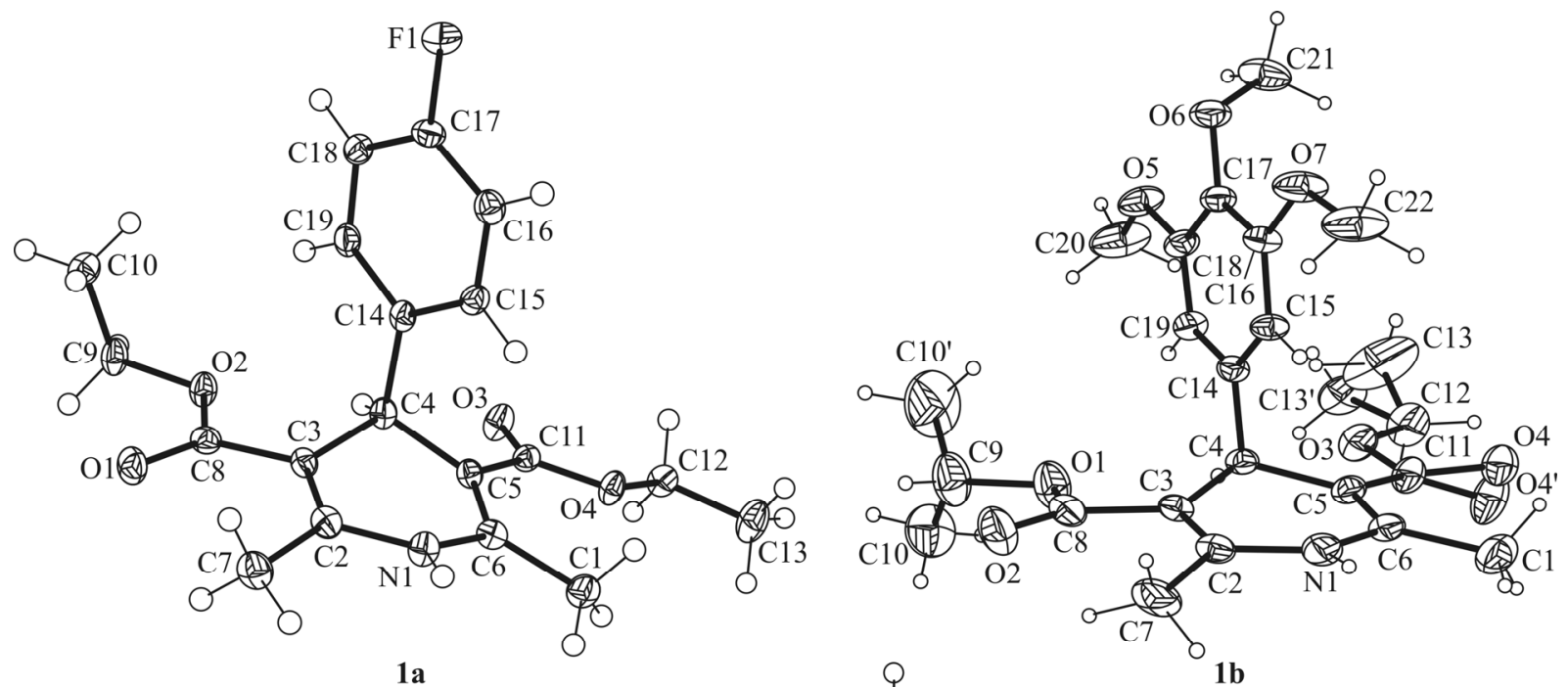

$1 \mathrm{a}$

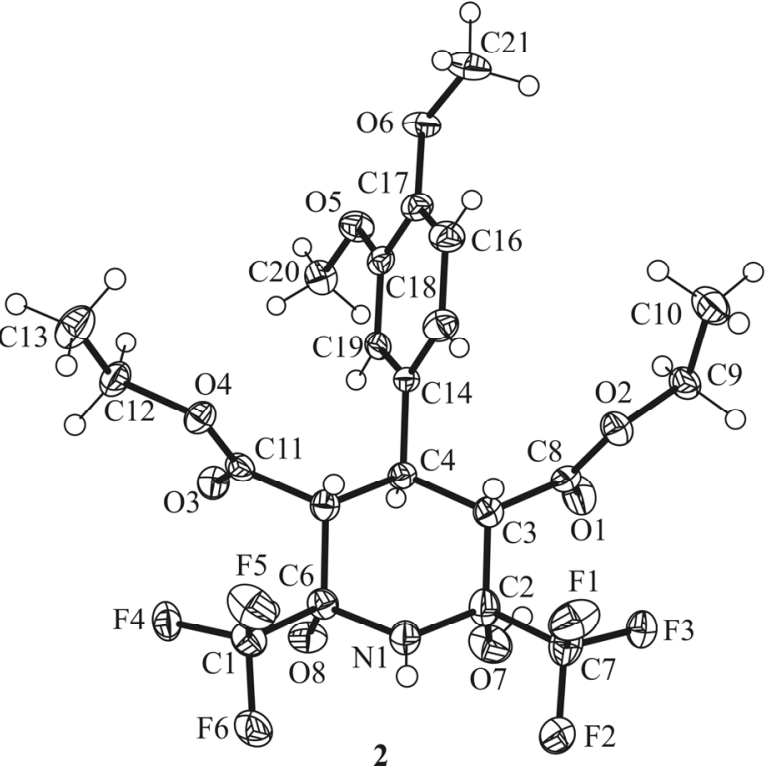

Fig. 1. ORTEP view of compounds $\mathbf{1 a}, \mathbf{1 b}$, and $\mathbf{2}$ with $50 \%$ probability ellipsoids and the atom numbering scheme.

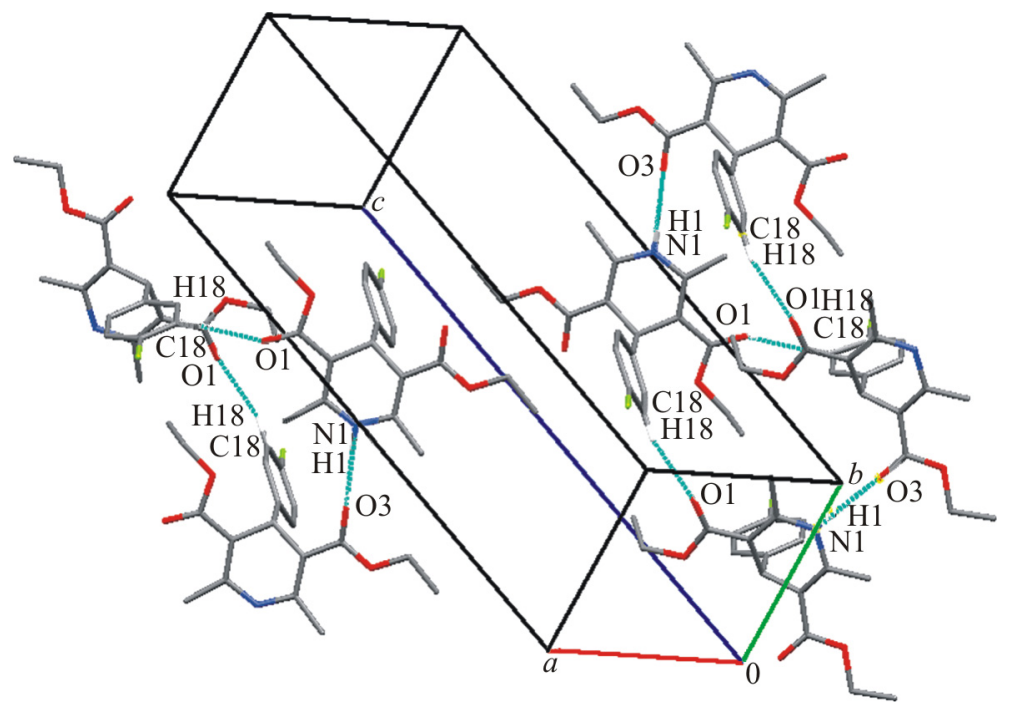

Fig. 2. Packing of compound 1a showing intermolecular $\mathrm{N}-\mathrm{H} \cdots \mathrm{O}$ and $\mathrm{C}-\mathrm{H} \cdots \mathrm{O}$ interactions. 


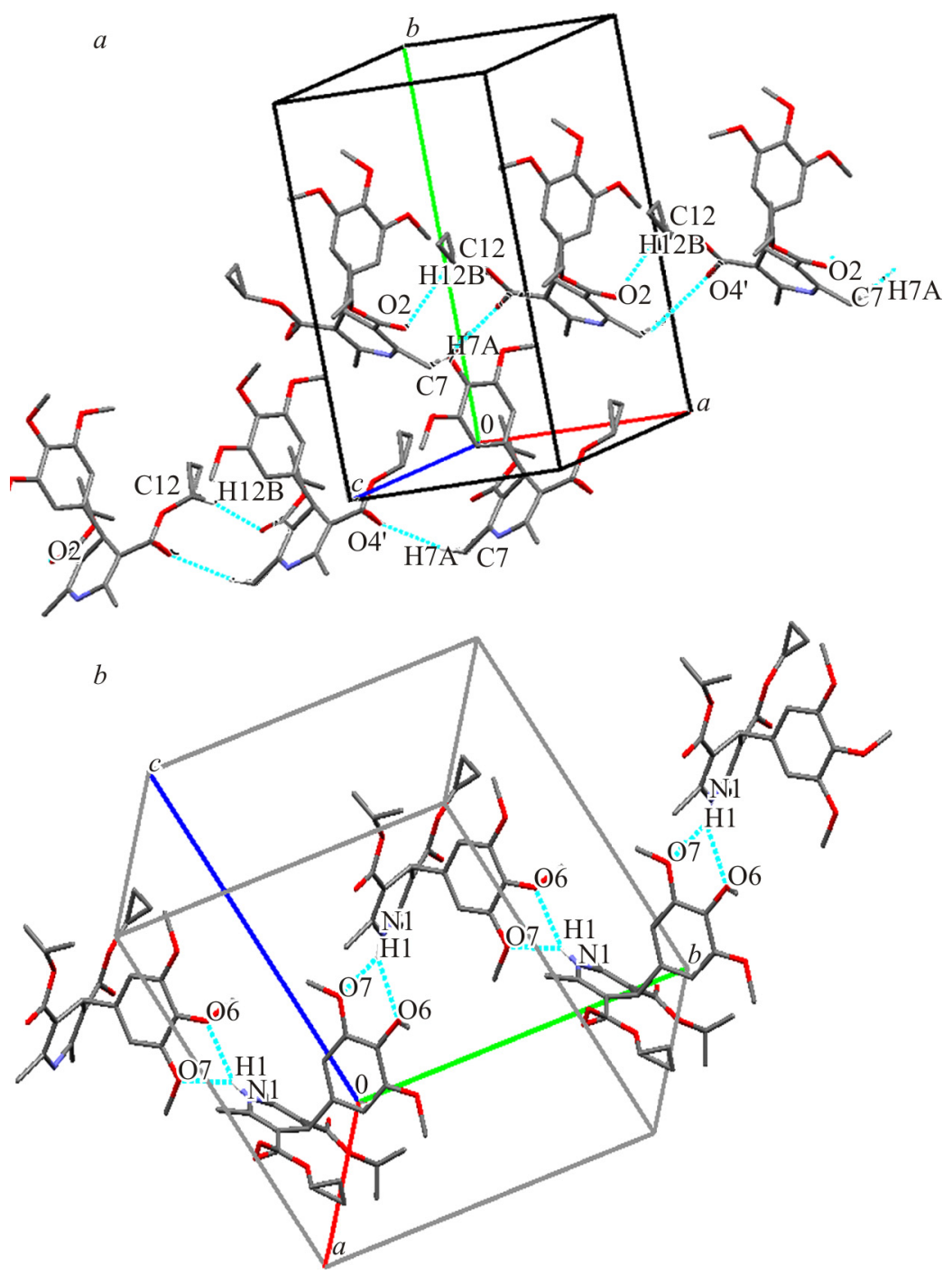

Fig. 3. Packing of compound $\mathbf{1 b}$ showing intermolecular, $\mathrm{C}-\mathrm{H} \cdots \mathrm{O}(a)$ and $\mathrm{N}-\mathrm{H} \cdots \mathrm{O}(b)$ interactions.

Owing to the importance of the $\mathrm{C}-\mathrm{F}$ bond, we have introduced fluorine atoms into the dihydropyridine nucleus at different positions. For instance, in compound 1a, the fluorine atom is at the para position of the phenyl ring, which is at the $\mathrm{C} 4$ position of the pyridine nucleus, and in compound 2, the trifluoromethyl group is substituted at $\mathrm{C} 1$ and $\mathrm{C} 7$ positions. As a result of these substitutions in compounds 1a (Fig. 2) and $\mathbf{2}$ (Fig. 4), we have observed different sets of interactions, such as the $\mathrm{C} 9-\mathrm{H} 9 \mathrm{~A} \cdots \mathrm{F}$ interaction in compound 1a, which is of a smaller angle $\left(132.2^{\circ}\right)$ and a $\mathrm{H} 9 \mathrm{~A} \cdots \mathrm{F}$ distance of $2.56 \AA$, and hence, is not considered in the stabilisation of the molecular lattice. However, in compound 2, N1-H1 $\cdots \mathrm{F} 2$ and C16H16 $\cdots$ F5 interactions (Fig. 2) are seen due to the presence of the trifluoromethyl group at C1 and C7 instead of the methyl group and are also considered as a strong, prominent interaction in holding the molecules together and further stabilisation. In compound $\mathbf{1 b}$ (Fig. 3), $\mathrm{N}-\mathrm{H} \cdots \mathrm{O}$ and $\mathrm{C}-\mathrm{H} \cdots \mathrm{O}$ interactions are observed, which further stabilizes the molecular lattice. All the three compounds lack intramolecular interactions. 

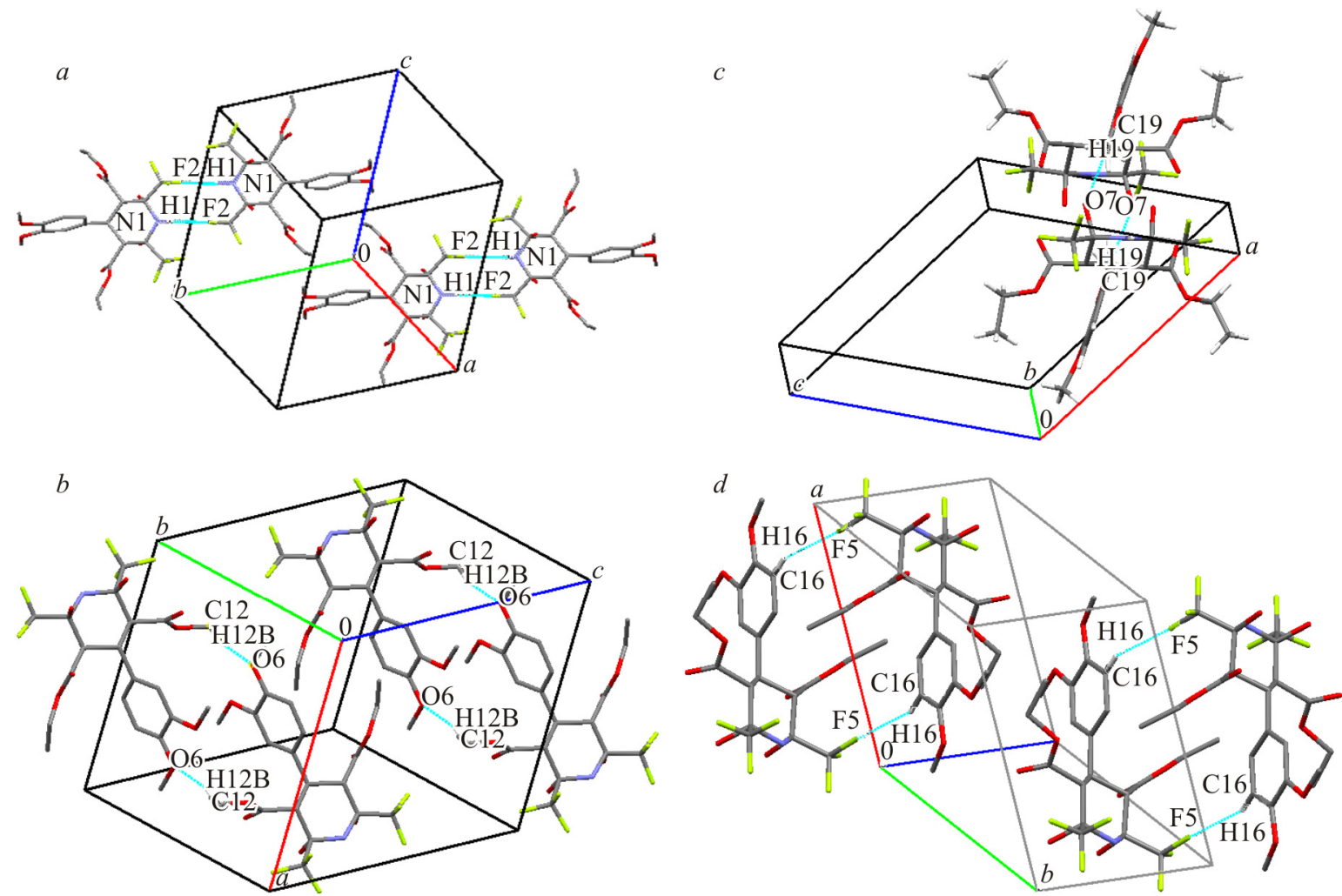

Fig. 4. Packing of compound 2 showing intermolecular $\mathrm{N}-\mathrm{H} \cdots \mathrm{F}(a), \mathrm{C}-\mathrm{H} \cdots \mathrm{O}(b, c)$, and interactions $\mathrm{C}-\mathrm{H} \cdots \mathrm{F}(d)$.

TABLE 6. Comparison of Various Compounds

\begin{tabular}{c|c|c|c|c}
\hline Crystal code & Crystal system & Space group & Dihedral angle, deg & Intermolecular interactions \\
\hline 1a & Monoclinic & $P 2_{1} / c$ & $87.23(6)$ & $\mathrm{C}-\mathrm{H} \cdots \mathrm{O}, \mathrm{N}-\mathrm{H} \cdots \mathrm{O}$ \\
1b & Orthorhombic & $P 2_{1} 2_{1} 2_{1}$ & $88.61(5)$ & $\mathrm{C}-\mathrm{H} \cdots \mathrm{O}, \mathrm{N}-\mathrm{H} \cdots \mathrm{O}$ \\
$\mathbf{2}$ & Triclinic & $P-1$ & $70.49(1)$ & $\mathrm{C}-\mathrm{H} \cdots \mathrm{F}, \mathrm{N}-\mathrm{H} \cdots \mathrm{F}, \mathrm{C}-\mathrm{H} \cdots \mathrm{O}$
\end{tabular}

\section{CONCLUSIONS}

The present work describes the synthesis of 1,4-DHP derivatives and their crystal structure analysis (Table 6). The insight into the self-assembly of these compounds shows various types of non-covalent interactions that have great influence on crystal packing.

The conformational study of their crystal structures, both concerning the 1,4-DHP ring and the substituents, as well as the study of intermolecular and hydrogen bonding interactions have added useful information for understanding the features of this class of compounds. The crystal structures are stabilized by $\mathrm{N}-\mathrm{H} \cdots \mathrm{F}, \mathrm{N}-\mathrm{H} \cdots \mathrm{O}, \mathrm{C}-\mathrm{H} \cdots \mathrm{O}$, and $\mathrm{C}-\mathrm{H} \cdots \mathrm{F}$ interactions.

\section{ADDITIONAL INFORMATION}

The CIF files have been deposited with the Cambridge Crystallographic Data Centre. The deposition number of compounds 1a, 1b, and $\mathbf{2}$ is CCDC-1889500, 1939480, and 1889485 respectively. These data can be obtained free of charge at www.ccdc.cam.ac.ul/conts/retrieving.html [or from the Cambridge Crystallographic Data Centre (CCDC), 12 Union Road, Cambridge CB2 1EZ, UK; fax: +44(0)1223-336033; email: deposit@ccdc.cam.ac.uk. 


\section{CONFLICT OF INTERESTS}

The authors declare that they have no conflict of interests.

\section{REFERENCES}

1. R. A. Janis, P. J. Silver, and D. J. Triggle. Adv. Drug Res., 1987, 16, 309.

2. F. Bossert and W. Vater. Med. Res. Rev., 1989, 9, 291.

3. B. Loev, M. Goodman, K. Snader, R. Tedeschi, and E. Macko. J. Med. Chem., 1974, 17, 956.

4. F. Bossert, H. Meyer, and E. Wehinger. Angew. Chem., Int. Ed., 1981, $20,762$.

5. V. M. Briukhanov, Ya. F. Zerev, and V. I. Elkin. Eksp. Klin. Farmakol., 1994, $57,47$.

6. A. Hilgroth and H. Lilie. Eur. J. Med. Chem., 2003, 38, 495.

7. B. R. P. Kumar, P. Masih, E. Karthikeyan, A. Bansal, Suja, and P. Vijayan. Med. Chem. Res., 2010, 19, 344.

8. A. S. Kermani, H. Shafaroodi, R. Miri, H. Mirkhani, M. Vosooghi, and A. Shafiee. Med. Chem. Res., 2009, $18,112$.

9. G. A. Wachter, M. C. Davis, A. R. Martin, and S. G. Franzblau. J. Med. Chem., 1998, 41, 2436.

10. K. Cooper, M. J. Fray, M. J. Parry, K. Richardson, and J. Steele. J. Med. Chem., 1992, 35, 3115.

11. S.-J. Choi, J.-H. Cho, I. Im, S.-D. Lee, J.-Y. Jang, Y.-M. Oh, Y.-K. Jung, E.-S. Jeon, and Y.-C. Kim. Eur. J. Med. Chem., 2010, 45, 2578 .

12. A. Davood, A. Nematollahi, M. Iman, and A. Shafiee. Arch. Pharmacal Res., 2009, 32, 481.

13. E. J. Roh, J. M. Keller, Z. Olah, M. J. Iadarola, and K. A. Jacobson. Bioorg. Med. Chem., 2008, 16, 9349.

14. K. Reichenbächer, H. I. Süss, and J. Hulliger. Chem. Soc. Rev., 2005, 34, 22-30.

15. T. V. Rybakova and I. Yu. Bagryanskaya. J. Struct. Chem., 2009, 50(4), 741-753.

16. F. Babudri, G. M. Farinola, F. Naso, and R. Ragni. Chem. Commun., 2007, 1003.

17. F. Leroux, P. Jeschke, and M. Schlosser. Chem. Rev., 2005, 105, 827.

18. K. Sirisha, M. Chandra Shekar, K. Umasankar, P. Mahendar, A. Sadanandam, G. Achaiah, and V. Malla Reddy. Bioorg. Med. Chem., 2011, 19, 3249.

19. A. Hantzsch. Justus Liebigs Ann. Chem., 1882, 215, 1.

20. A. S. Kotharkar and B. D. Shinde. Ukr. Bioorg. Acta, 2006, 1, 3.

21. S.-X. Wang, Z.-Y. Li, J.-C. Zhang, and J.-T. Li. Ultrason. Sonochem., 2008, 15, 677.

22. J. Legeay, J. J. V. Eyndeb, and J. P. Bazureau. Tetrahedron, 2005, 61, 12386.

23. S. Deshayes, M. Liagre, A. Loupy, J.L. Luche, and A. Petit. Tetrahedron, 1999, 55, 10851.

24. W. H. Correa and J. L. Scott. Green Chem., 2001, 3, 296.

25. R. S. Varma. Green Chem., 1999, 1, 43.

26. S. D. Sharma, P. Hazarika, and D. Konwar. Catal. Commun., 2008, 9, 709.

27. M. Li, Z. Zuo, L. Wen, and S. Wang. J. Comb. Chem., 2008, 10, 436.

28. Bruker. SMART, SAINT-Plus and SADABS. Madison, Wisconsin, Bruker AXS: USA, 1998.

29. G. M. Sheldrick. Acta Crystallogr., Sect. A, 2008, 64, 112.

30. M. Nardelli. Acta Crystallogr., Sect. C, 1983, 39, 1141.

31. L. J. Farrugia. J. Appl. Crystallogr., 1997, 30, 565.

32. K. Brandenburg, H. Putz. DIAMOND. Crystal Impact GbR: Bonn, Germany, 2005.

33. D. O'Hagan. J. Org. Chem., 2012, 77, 3689-3699.

34. V. H. Dalvi and P. J. Rossky. Proc. Natl. Acad. Sci. U. S. A., 2010, 107, 13603-13607.

35. P. Fenter. Langmuir, 1997, 7, 2013-2016. 